\title{
Timely detection of bronchiolitis epidemics in Guadeloupe ${ }^{1}$
}

\author{
Martina Escher, ${ }^{2}$ Philippe Quénel,,2 Jean-Loup Chappert, ${ }^{2}$ \\ and Sylvie Cassadou ${ }^{2}$
}

Suggested citation Escher M, Quénel P, Chappert JL, Cassadou S. Timely detection of bronchiolitis epidemics in Guadeloupe. Rev Panam Salud Publica. 2012;32(2):87-92.

\begin{abstract}
Objective. To develop a criterion for early detection of bronchiolitis epidemics in Guadeloupe so that prevention and control strategies can be implemented in a more timely manner. Methods. Weekly figures of bronchiolitis cases reported from July 2005-July 2010 by Guadeloupe's sentinel network were used. The criterion for detecting epidemics was created with data from the 2005-2009 bronchiolitis seasons. First, the baseline level for bronchiolitis (BL) was predicted by fitting a periodic regression on the non-epidemic observations; then a test was conducted of nine possible criteria to define epidemics by combining a statistical threshold set at different levels and a number of consecutive weeks with observations above and below them; lastly, the optimal criterion was selected considering its performances using expert advice as the gold standard. The selected criterion was validated with data from 2009-2010 season.

Results. The BL accounted for a linear trend and two sinusoidal functions of 52 and 26 weeks $(R 2=45 \%)$. According to the epidemic criterion selected, the statistical threshold was set at the upper limit of the one-sided 95\% Confidence Interval of the predicted BL; 2 consecutive weeks with cases above it were necessary to set the start of an epidemic, and three again below to set the end. The median delay in launching the alerts was 2 weeks; there was one false alert; and the sensitivity, specificity, and positive predictive value for detecting epidemic weeks were $98 \%, 96 \%, 95 \%$, respectively. During the validation period, the criterion launched one false alert and detected the epidemic with 4 weeks of delay.

Conclusions. This criterion supports epidemiologists in timely interpretation of bronchiolitis epidemiological data for decision makers in Guadeloupe. In the future, it should be updated in accordance with trends in bronchiolitis epidemiology, and improved by integrating virological indicators. Its inclusion in an integrated management strategy for bronchiolitis prevention and control, supported by a bronchiolitis public health network, should also be encouraged.
\end{abstract}

Key words Bronchiolitis, viral; bronchiolitis; Guadeloupe; France; Caribbean region.

It is well known that early detection of epidemics is imperative to effective control; hence, infectious disease sur-

\footnotetext{
1 Preliminary results of the study were presented at the European Scientific Conference on Applied Infectious Disease Epidemiology; in Lisbon, Portugal, 2010 (Abstract 2010329).

2 Cellule de l'Institut de Veille Sanitaire en Régions Antilles Guyane, Fort de France, Martinique, France. Send correspondence to: Martina Escher, martina.escher@gmail.com
}

veillance has been conducted in many countries for decades. Traditional methods of reporting diseases (e.g., notifiable disease surveillance, laboratory-based surveillance) are currently linked to less specific, but more reactive methods (1). These include syndromic surveillance, which makes it possible to identify illness clusters before diagnoses are confirmed (1-3), and mathematical models, which are often used to analyze surveillance data in order detect epidemics sooner (4-9).

Throughout the world, acute bronchiolitis is a common lower respiratory tract infection and a leading cause of hospital admission among young children, especially those less than 2 years of age (10). In France, an estimated one-third of the infant population is affected each 
year, thus more than 450000 infants (11). This clinically-diagnosed viral respiratory condition can be caused by several viruses, but the most common is respiratory syncytial virus (RSV), which is isolated in as many as $75 \%$ of cases $(10,12)$.

Bronchiolitis is usually seasonal, with epidemics occurring every year, and in the majority of cases, is only mildly self-limiting (11-14). Nevertheless, the public health burden of bronchiolitis is considerable - the high number of infants seeking care during epidemics has a considerable impact on any health care system $(13,14)$. Many health sector stakeholders-pediatricians, general practitioners (GPs), physiotherapists, emergency units, hospitals, and health promotion communicators- are affected by bronchiolitis epidemics (14). Coordination and collaboration among these stakeholders are key to launching timely preventive strategies and responding appropriately at the community-level so that emergency units are not overwhelmed. To this end, early detection of bronchiolitis epidemics is imperative.

In Guadeloupe, a French territory located in the West Indies, bronchiolitis has been monitored since 2003 by a syndromic surveillance system based on a network of sentinel GPs (15). Cases are reported weekly throughout the year; seasonal epidemics occur in September-December.

This study was undertaken to develop a criterion based on the aforementioned surveillance system that would improve the timeliness of bronchiolitis epidemic detection in Guadeloupe. This article presents the methods employed and the performance of this epidemic criterion.

\section{MATERIALS AND METHODS}

\section{Data source}

A syndromic, sentinel surveillance system based on a network of GPs began operating in Guadeloupe in 1983; in 2003, bronchiolitis was placed under surveillance (7). Since 2005, the network has been made up of 44 GPs who, according to the Caisse Générale de Sécurité Sociale de la Guadeloupe (General Social Security Fund of Guadeloupe, CGSS), account for $12 \%$ of the total number of GPs in Guadeloupe and $20.4 \%$ of its overall medical activities (15). Within the framework of the surveillance system, a case of bronchiolitis has been defined as: (i) a child less than 2 years of age (ii) pre-
FIGURE 1. Weekly number of bronchiolitis cases among children less than 2 years of age in Guadeloupe, France, 25 July 2005-25 July 2010

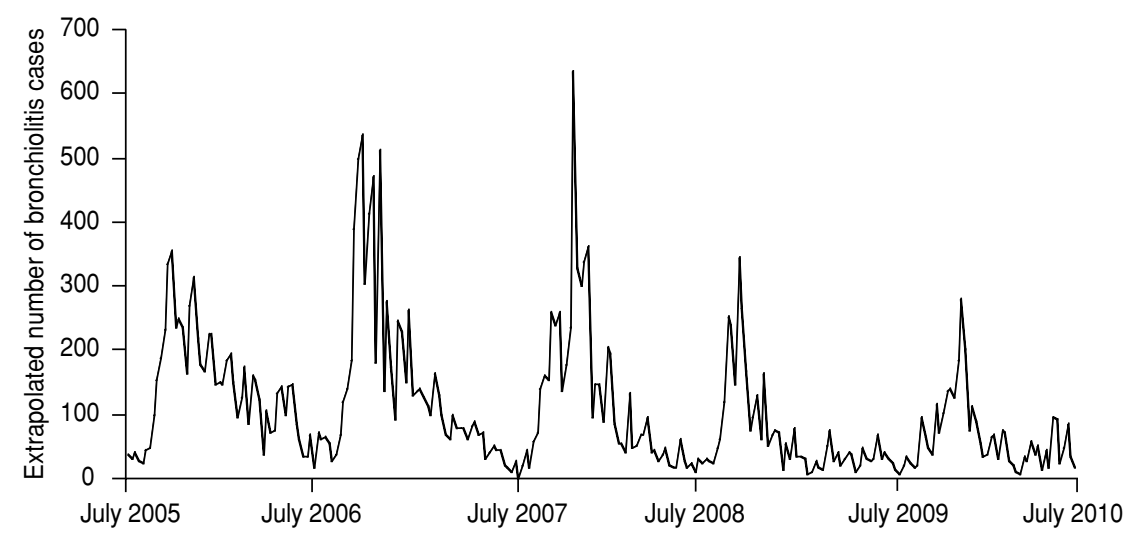

senting expiratory dyspnea and obstructive signs, with (iii) difficulty coughing, and (iv) in an infectious context (15).

Guadeloupe's health agency collects case numbers by telephone on a weekly basis. In order to stabilize the figures and overcome the effect of the variable participation of the sentinel GPs, the number of cases reported weekly is divided by the cumulated activity fraction of sentinel GPs at work that specific week. For each sentinel GP, the activity fraction is calculated from the CGSS data from the previous year (16).

This study analyzed weekly data from 25 July 2005-25 July 2010 (Figure 1). The criterion for early detection and monitoring of bronchiolitis epidemics was developed with data for July 2005-July 2009, and subsequently validated with data from July 2009-July 2010.

\section{Criterion development}

The criterion was developed in two steps: first, the "baseline level" of bronchiolitis was estimated; and then, the criterion was created to define epidemic periods (i.e., start and end weeks). These two steps are detailed below.

Prediction of bronchiolitis baseline. The Internet application, Réseau Sentinelles ${ }^{\circledR}$ (French National Institute of Health and Medical Research and the Pierre and Marie Curie University, Paris, France) (8), was used to fit a periodic regression (also known as Serfling's method) on the non-epidemic observations for the period 2005-week 30-2009-week 29. To exclude the epidemic observations, a cut-off value was set at the upper unilat- eral 95\% Confidence Interval $(95 \% \mathrm{CI})$ of the mean of all the observations.

The structure of the periodic regression model was composed of a trend (a first degree polynomial function of the time) plus one or two seasonal components (sine and cosine terms with annual, or annual plus semi-annual periodicities). The two periodic regression equations were a special case of the following model:

$$
\begin{aligned}
Y_{\mathrm{t}} & =\alpha+\beta_{\mathrm{t}}+\gamma_{1} \cos (2 \pi \mathrm{t} / \mathrm{n})+\delta_{1} \sin (2 \pi \mathrm{t} / \mathrm{n}) \\
& +\gamma_{2} \cos (4 \pi \mathrm{t} / \mathrm{n})+\delta_{2} \sin (4 \pi \mathrm{t} / \mathrm{n})+\varepsilon
\end{aligned}
$$

In this model, $Y_{t}$ is the number of bronchiolitis cases at week $t ; \alpha$ and $\beta$ are the intercept and the slope of the linear regression; $\gamma_{1,2}$ and $\delta_{1,2}$ are the parameters of the seasonal components; and $\varepsilon$ is the random error.

Model coefficients were estimated by the least-squares method. The validity of the model was tested by verifying the homoscedasticity of residuals through graphical analysis, statistical analysis of their distribution, and their independence by the Ljung-Box test. The fit of the model was assessed by the coefficient of determination (R2). The Akaike's information criterion (AIC) was used to identify, among different models, the one that fits the data better, based on the parsimony principle. Finally, the selected model was used to predict the "baseline level" of bronchiolitis cases in Guadeloupe for the period 2005-2009.

Definition of epidemic periods. In order to define the start and end weeks of an epidemic (i.e., to distinguish between the significant departures of an observation 
from the expected baseline level and a random variation), two parameters were combined: (i) a statistical threshold, and (ii) a number of consecutive weeks with a number of bronchiolitis cases respectively above and below the threshold. The threshold was defined as the upper limit of the one-sided CI of the predicted baseline level, the variation around the baseline level being established on the standard deviation of the residuals. Three $\alpha$ levels were used: $0.1,0.5$, and 0.01. As the number of consecutive weeks above and again below the threshold is concerned, 1, 2, or 3 were used as the options for setting the start of the epidemics, and 3 was used to set the end.

Combining these two parameters, nine possible criteria were identified and studied. To assess their performance, the results of these nine criteria were compared to a gold standard established by expert advice. ${ }^{3}$ Performance was based on: (i) the speed with which epidemic alerts were launched; (ii) the number of false alerts, i.e., epidemic periods detected outside the gold standard; (iii) sensitivity, i.e., the ability to identify epidemic weeks within the gold standard; (iv) specificity, i.e., the ability to detect true non-epidemic weeks; and (v) the positive predictive value (PPV), i.e., how precisely true epidemic weeks were detected.

The best criterion had to combine timely epidemic warnings with a low number of false alerts and a high sensitivity, specificity, and PPV in correctly detecting the epidemic weeks.

\section{Criterion validation}

The final selected model was used to forecast the baseline level of bronchiolitis cases in Guadeloupe in the 2009-2010 season. The epidemic criterion retained was validated by comparing the epidemic periods detected by the study's tool (in terms of start and duration) with those indicated by the expert.

\section{RESULTS}

In Guadeloupe, a linear decrease in the number of bronchiolitis cases was

\footnotetext{
3 Jean-Loup Chappert, epidemiologist with 15 years of clinical practice, public health field operations, and public health administration experience, and an active participant in the infectious disease surveillance and alert component of disease control in Guadeloupe.
}

observed during the study period, with 7200 estimated cases in the 2005-2006 season and 3200 in the 2009-2010 season. The incidence of bronchiolitis was highly seasonal, and the lowest number of cases occurred in July. Each year, epidemics occurred around mid-October and mid-December. They started sharply and ended smoothly with strong interweekly fluctuations. During the study period, a decrease in their amplitude and duration was observed.

\section{Criterion development}

Prediction of bronchiolitis baseline. According to the cut-off value, the baseline level was estimated by fitting the model on 128 non-epidemic observations. According to the AIC criterion, the best model consisted of a linear trend and 12- and 6-month periodicities, which accounted for $45 \%$ of the variance of the time series $(\mathrm{R} 2=0.45)$ (Figure 2$)$ :

$$
\begin{gathered}
Y_{t}=91.9-0.2 t+22.175 \cos (2 \pi t / 52.2) \\
-1.7 \sin (2 \pi t / 52.2)-6.0 \cos (4 \pi t / 52.2) \\
-12.8 \sin (4 \pi t / 52.2)+\varepsilon_{t}
\end{gathered}
$$

Using this model, three statistical thresholds were calculated at $0.1,0.05$, and 0.01 $\alpha$ level (Figure 2).

Definition of epidemic periods. Between July 2005 and July 2009, four bronchiolitis epidemics, one each season, accounting for 101 epidemic weeks, were identified by the expert advice (gold standard) (Table 1).

All nine of the criteria studied enabled the detection of epidemic periods with respect to the gold standard. The performances of these criteria are presented in Table 2. According to these results, the best criterion was $\mathrm{ST}_{\alpha \text { level } 0.05}\left(\mathrm{SW}_{2}-\right.$ $\mathrm{EW}_{3}$ ), with a median delay of 2 weeks for launching the epidemic alert; only one false alert; and sensitivity, specificity, and PPV of $98 \%, 96 \%$, and $95 \%$, respectively.

\section{Criterion validation}

According to the expert advice, the 2009-2010 bronchiolitis season was characterized by one epidemic period occurring between 2009-week 43 and 2009-week 53 (Figure 3, green area). The

FIGURE 2. Baseline of bronchiolitis and statistical thresholds, Guadeloupe, France, 25 July 2005-20 July 2010

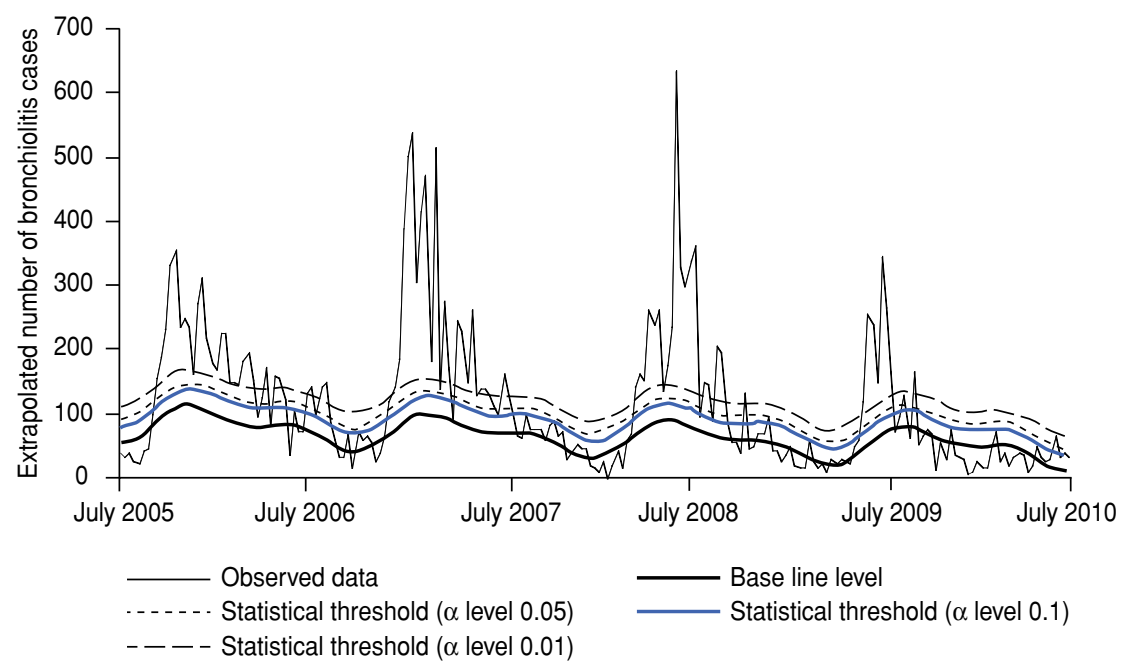

TABLE 1. Bronchiolitis epidemics as defined by expert advice (gold standard), Guadeloupe, France, 2005-2009

\begin{tabular}{cccc}
\hline Season & Week of onset & Week of offset & Duration (in weeks) \\
\hline $2005-2006$ & $2005-37$ & $2006-14$ & 30 \\
$2006-2007$ & $2006-37$ & $2007-12$ & 28 \\
$2007-2008$ & $2007-39$ & $2008-05$ & 20 \\
$2008-2009$ & $2008-36$ & $2008-47$ & 12 \\
\hline
\end{tabular}


TABLE 2. Timeliness, number of false warnings launched, sensitivity, specificity, and positive predictive value (PPV) of the nine epidemiological criteria studied for the detection and monitoring of bronchiolitis epidemics, compared to the gold standard, Guadeloupe, July 2005-July 2009

\begin{tabular}{|c|c|c|c|c|c|c|}
\hline \multicolumn{2}{|c|}{ Criteria } & \multicolumn{5}{|c|}{ Attributes } \\
\hline $\begin{array}{l}\text { Statistical } \\
\text { threshold (ST) }\end{array}$ & $\begin{array}{c}\text { Starting week } \\
(\mathrm{SW} 1 ; 2 ; 3)^{\mathrm{a}} \text { and } \\
\text { ending week (EW3) }\end{array}$ & $\begin{array}{c}\text { Timeliness }^{c} \\
\text { (range) }\end{array}$ & $\begin{array}{l}\text { No. of false } \\
\text { warning } \\
\text { launched }\end{array}$ & $\begin{array}{c}\text { Sensitivity } \\
\%\end{array}$ & $\begin{array}{c}\text { Specificity } \\
\%\end{array}$ & PPV\% \\
\hline \multirow[t]{3}{*}{$\mathrm{ST}_{\alpha \text { level } 0.1}$} & (SW1-EW3) & $1(1-2)$ & 3 & 97.78 & 93.22 & 91.67 \\
\hline & (SW2-EW3) & $2(2-3)$ & 1 & 97.78 & 94.92 & 93.62 \\
\hline & (SW3-EW3) & $3(3-4)$ & 1 & 97.78 & 94.92 & 93.62 \\
\hline \multirow{3}{*}{$S T_{\alpha \text { level } 0.05}$} & (SW1-EW3) & $1(1-2)$ & 3 & 97.78 & 93.97 & 92.63 \\
\hline & (SW2-EW3) & $2(2-3)$ & 1 & 97.78 & 95.73 & 94.62 \\
\hline & (SW3-EW3) & $3(3-4)$ & 0 & 96.67 & 100.00 & 100.00 \\
\hline \multirow{3}{*}{$S T_{\alpha \text { level } 0.01}$} & (SW1-EW3) & $1.5(1-2)$ & 2 & 91.11 & 94.92 & 93.18 \\
\hline & (SW2-EW3) & $2.5(2-3)$ & 1 & 90.00 & 95.76 & 94.19 \\
\hline & (SW3-EW3) & $3.5(3-4)$ & 0 & 90.00 & 100.00 & 100.00 \\
\hline
\end{tabular}

a SW is the number of consecutive week $(1,2$, or 3$)$ with an exceeding number of extrapolated bronchiolitis cases needed in order to launch the warning.

${ }^{b} \mathrm{EW}_{3}$ refers to the 3 consecutive weeks with a number of extrapolated bronchiolitis cases again below the threshold needed to set the end of the epidemics.

c Median number of weeks of delay in launching the alerts.

FIGURE 3. Validation of the epidemiological criterion according to weekly number of bronchiolitis cases among children less than 2 years of age in Guadeloupe, France, 20 July 2009-25 July 2010

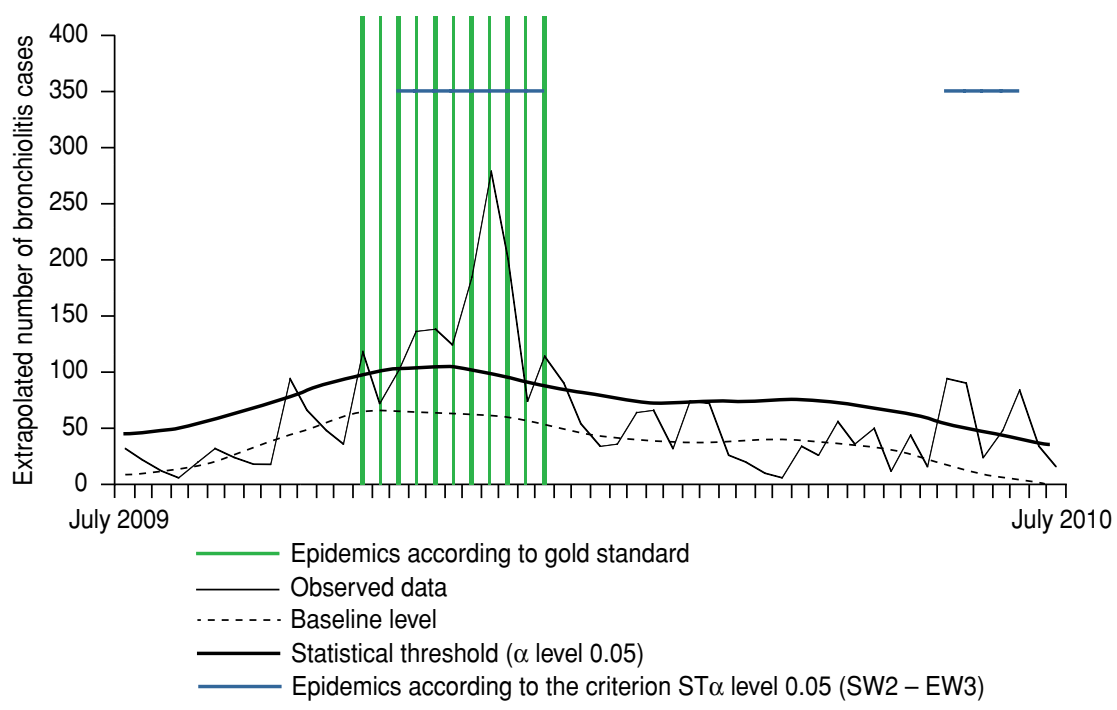

selected criterion detected 2 epidemic periods (Figure 3, grey straight lines), the second being a false alert. Considering the first epidemic, the criteria launched the warning with a delay of 4 weeks, 2 weeks later than the expert advice, and correctly established the end of the epidemic.

\section{DISCUSSION}

By analyzing the historical time-series data of the syndromic bronchiolitis surveillance in Guadeloupe, a criterion was developed for the detection of epidemics. This criterion showed good performance in terms of timeliness ( 2 weeks of median delay), sensitivity, specificity, and PPV
(98\%, 96\%, 95\%, respectively). However, this performance was only partially observed during the validation period.

Concerning the methods, because the identification of abnormally high occurrences of a disease relies on a good understanding of the normal patterns of its occurrence (6), the first step was applying time-series analysis methods to establish a baseline level. Time series analysis is especially suitable for baseline level detection because it uses historical data for non-epidemic periods to predict what future data should be in the absence of an epidemic (7).

Different methods have been used for this purpose, such as Seasonal Auto
Regressive Integrated Moving Average (SARIMA) models, control chart methods, and Hidden Markov Models (8). In this study, an online application was employed that uses a model based on a regression with seasonal components. This approach was chosen because the type of analysis proposed fit the characteristics of the study's time series well (at least 2 or 3 years of historical data, time series characterized by a marked seasonal variation of the additive type with outbreak, and the absence of discontinuities or large breaks) (8).

Then, the start week of each epidemic was defined by combining a statistical threshold (with three levels) and a variable number of consecutive weeks with a figure above and below it. Both of these parameters impacted criteria performance. The $\alpha$ level of the statistical threshold mostly impacted the sensitivity of detecting the epidemic weeks. Conversely, the criterion's specificity was directly linked to the number of consecutive weeks needed to set the start of an epidemic. Experience has shown that while an increase in the number of cases above the epidemic threshold for a single week is often accounted for by a data transmission error or other extraneous factors, a high level of cases for 2 or more consecutive weeks usually indicates a true rise in incidence (17).

Inevitably, a trade off exists between precision and timeliness when detecting epidemics. From a public health point of view, it is important to balance the risk of wrongly launching an epidemic alert—which entails economic waste and 
public health implications-with that of launching it so late that the measures will be ineffective or effective too late. With this in mind, the criterion $\mathrm{ST}_{\alpha \text { level } 0.05}$ $\left(\mathrm{SW}_{2}-\mathrm{EW}_{3}\right)$ was chosen because it coupled good timeliness and specificity in launching epidemic alerts with a sensitivity, specificity, and PPV in detecting the epidemic weeks not lower than 95\%. However, these good performances were only partially observed during the validation period.

Nonetheless, it is important to consider that the expert was asked to identify epidemic periods retrospectively. The a posterior analysis of surveillance data enables the interpretation of data for a specific week while being aware of what the figures are for the week that follows it, information not available when analyzing data on a real-time base. In this case, the additional information drove the expert to set the start of the epidemic for the 2009-2010 season in a week still characterized by an inter-weekly fluctuation, and to disregard a second period of increase as an epidemic.

Indeed, the 2009-2010 bronchiolitis season was peculiar, compared to the previous ones, with a steady increase of cases in the first phase of the epidemics compared to the sudden, dramatic increase seen in previous years. This may have been caused by a pandemic influenza A (H1N1) wave that swept Guadeloupe in mid-August 2009, prior to influenza season, which generally starts in midDecember. In fact, some authors suggest the possibility that the $2009 \mathrm{H} 1 \mathrm{~N} 1$ wave impacted the usual dynamics of the hibernal viruses due to an interaction among respiratory viruses (18). Moreover, it is possible that the H1N1 epidemic influ- enced the practices of physicians in diagnosing respiratory syndromes in children, making GPs more prone to classify them as influenza cases.

Those hypotheses are difficult to assess since Guadeloupe currently lacks a laboratory-based surveillance system for viral respiratory infections other than influenza (e.g., RSV, human parainfluenza viruses, adenovirus, etc.). Information on the circulation of respiratory viruses could support the interpretation of syndromic data.

Regarding the GPs'capacity to correctly classify cases, it should be taken into account that bronchiolitis occurs mainly in children less than 2 years of age with specific clinical symptoms that generally differ from those of influenza. As a consequence, the definitions adopted by the surveillance system for bronchiolitis and influenza-like syndromes are fairly different (15) and have not changed over the years. Nonetheless, results from a recent study on GPs' attitude in the management of bronchiolitis cases in young infants in France suggest that moderate acute bronchiolitis cases were recognized in $59 \%$ and $68 \%$ of cases in 2003 and 2008, respectively (19). Sentinel GPs in Guadeloupe are generally a well-sensitized physician population, however their classification of cases according to surveillance definitions could be assessed to identify any gaps.

Although the authors consider the syndromic surveillance system in Guadeloupe to be a good tool for monitoring bronchiolitis, and the criterion developed to be a sound step toward more rapid epidemic detection, further improvements are recommended, specifically: the addition of other syndromic health services- based indicators (e.g., emergency department activities), and more importantly, a laboratory-based surveillance system, analogous to those currently operating in other areas of France (13).

\section{Conclusions}

Given that bronchiolitis is a major cause of morbidity in young children, preparedness, early detection, and timely response to its outbreaks are imperative and key to prevention and control. The epidemic criterion presented in this paper will help epidemiologists in charge of bronchiolitis surveillance interpret data and issue public health alerts.

In the future, two main challenges will need to be addressed: first, annually updating the statistical threshold according to epidemiologic trends in bronchiolitis, and integrating new indicators into the epidemic criterion; and second, the inclusion of this epidemic criterion in an integrated management strategy for bronchiolitis prevention and control, in par with what has already been achieved for dengue (20). With these aims in mind, the organization of a bronchiolitis public health network in Guadeloupe should be encouraged, as it has been in other parts of France (21).

Acknowledgements. The authors would like to acknowledge Alicia Barrasa and Ioannis Karagiannis for providing valuable expertise during the course of the project. The authors also wish to thank the European Programme for Intervention Epidemiology Training (EPIET, Stockholm, Sweden) for funding this study through the first author's (ME) fellowship.

\section{REFERENCES}

1. Deseclos JC. Are there "new" and "old" ways to track infectious disease hazards and outbreaks? Euro Surveill. 2006;11(12). Available from: http:/ / www.eurosurveillance.org/ ViewArticle.aspx?ArticleId=663. Accessed 30 January 2012.

2. Henning KJ. What is syndromic surveillance? MMWR Morb Mortal Wkly Rep. 2004;Sep 24 (53 Suppl):5-11.

3. Josseran L, Nicolau J, Caillère N, Astagneau P, Brücker G. Syndromic surveillance based on emergency department activity and crude mortality: two examples. Euro Surveill. 2006;11(12). Available from: http:/ / www.euro surveillance.org/ViewArticle.aspx?ArticleId= 668. Accessed 30 January 2012.
4. Castagnola D, Flahault A, Galinec D, Garnerin $\mathrm{P}$, Menares J, Valleron AJ. A routine tool for detection and assessment of epidemics of influenza-like syndromes in France. Am J Public Health. 1991;81:97-9.

5. Allard R. Use of time-series analysis in infectious disease surveillance. Bull WHO. 1998;76(4):327-3.

6. Quenel P, Dab W. Influenza A and B epidemic criteria based on time-series analysis of health services surveillance data. European J Epidemiol. 1998;14:275-85.

7. Reis BY, Mandl KD. Time series modelling for syndromic surveillance. BMC Med Inform Decis Mak. Available from: http://www. biomedcentral.com/1472-6947/3/2 Accessed 30 January 2012.
8. Pelat C, Boëlle PY, Cowling BJ, Carrat F, Flahault A, Ansart S, Alain-Valleron AJ. Online detection and quantification of epidemics. BMC Med Inform Decis Mak. 2007; 7:29.

9. Hafen RP, Anderson DE, Cleveland RW, Ebert DS, Abusalah A, Yacout M, et al. Syndromic surveillance: STL for modelling, visualizing, and monitoring disease counts. BMC Med Inform Decis Mak. 2009;9:21.

10. Wainwright C. Acute viral bronchiolitis in children-a very common condition with few therapeutic options. Paediatr Respir Rev. 2010;11(1):39-45.

11. Grimprel E. Epidemiologie de la bronchiolite du nourrisson en France. Arch Pediatr. 2001;8(Suppl 1):83S-92S. 
12. Bush A, Thomson H. Acute bronchiolitis. BMJ 2007; 335:1037-41.

13. Caillère $N$, Josseran L. Surveillance and epidemiology of infant bronchiolitis in France. Arch Pediatr. 2008;15(3):327-8.

14. Union Régionale des Médecins Liberaux, Agence Nationale d'Accreditation et d'Evaluation en Santé. Conférence de consensus : Prise en charge de la bronchiolite du nourrisson. Edinburgh: Scottish Intercollegiate Guidelines Network; 2006. Available from: www.has-sante.fr/portail/upload/docs/ application/pdf/bronchio.pdf Accessed 30 January 2012.

15. Cassadou S. Le réseau de médecins sentinelles en Guadeloupe. Bulletin d'Alerte et de Surveillance Antilles Guyane. 2008;10: 3-4. Available from: http://www.invs.sante.fr/ publications/basag/basag2008_10.pdf Accessed 30 January 2012.
16. Cardoso T, Quenel P. Les réseaux de médecins sentinelles dans les départements français d'Amérique. Bulletin d'Alerte et de Surveillance Antilles Guyane. 2008;10: 2-3. Available from: http://www.invs.sante.fr/ publications/basag/basag2008_10.pdf Accessed 30 January 2012.

17. Serfling RE. Methods for current statistical analysis of excess pneumonia-influenza deaths. Public Health Rep. 1963;78:494-506.

18. Casalegno JS, Ottmann M, BouscambertDuchamp M, Valette M, Morfin F, Lina B. Impact of the 2009 influenza $A(H 1 N 1)$ pandemic wave on the pattern of hibernal respiratory virus epidemics, France, 2009. Euro Surveill. 2010;15(6). Available from: www.eurosurveillance.org /ViewArticle.aspx?ArticleId=19485. Accessed 30 January 2012.

19. David M, Luc-Vanuxem C, Loundou A, Bosdure E, Auquier P, Dubus J-C. Assess- ment of the French Consensus Conference for Acute Viral Bronchiolitis on outpatient management: Progress between 2003 and 2008 . Arch Pediatr. 2010;17(2):125-31.

20. Cire Antilles-Guyane. Integrated management strategy for dengue prevention and control in the Caribbean subregion. Bulletin de Veille Sanitaire Antilles Guyane. 2009;8:2-15. Available from: www.invs.sante.fr/publications/ bvs/antilles_guyane/2009/bvs8ag82009_08. pdf Accessed 30 January 2012.

21. Sebban S. La France des réseaux bronchiolite. Réseaux, Santé \& Territoir. 2010; 33(10):14-9.

Manuscript received on 10 December 2011. Revised version accepted for publication on 13 April 2012.

RESUMEN Objetivo. Formular un criterio para la detección temprana de las epidemias de bronquiolitis en Guadalupe, a fin de aplicar de manera más oportuna mejores estrategias de prevención y control.

Detección oportuna

Métodos. Se usaron las cifras semanales de los casos de bronquiolitis notificados desde julio del 2005 hasta julio del 2010 por la red de vigilancia de Guadalupe. El criterio para detectar las epidemias se estableció con los datos de las temporadas de bronquiolitis del 2005 al 2009. En primer lugar, se predijo el nivel basal de bronquiolitis ajustando una regresión periódica a los casos observados fuera de las epidemias; luego se pusieron a prueba nueve posibles criterios para definir las epidemias combinando un umbral estadístico establecido a diferentes niveles y un número de semanas consecutivas con las observaciones ubicadas por encima y por debajo de ellos; por último, se seleccionó el criterio óptimo conforme a su desempeño, usando el asesoramiento de expertos como criterio de referencia. El criterio seleccionado se validó con los datos de la temporada 2009-2010.

Resultados. El nivel basal de bronquiolitis presentaba una tendencia lineal y dos funciones sinusoidales de 52 y 26 semanas ( $2=45 \%$ ). Según el criterio de epidemia seleccionado, se fijó el umbral estadístico en el límite superior del intervalo de confianza de 95\% unilateral del nivel basal de bronquiolitis previsto; para establecer el comienzo de una epidemia se requerían 2 semanas consecutivas con casos por encima de él, y 3 semanas con casos por debajo para determinar su finalización. La mediana del retraso para lanzar las alertas fue 2 semanas; hubo una alerta falsa; y la sensibilidad, la especificidad y el valor predictivo positivo para detectar las semanas de epidemia fueron $98 \%, 96 \%$ y 95\%, respectivamente. Durante el período de validación se emitió, según el criterio, una alerta falsa y se detectó la epidemia con 4 semanas de retraso.

Conclusiones. Este criterio ayuda a los epidemiólogos a interpretar de manera oportuna los datos epidemiológicos de bronquiolitis a fin de tomar decisiones en Guadalupe. En el futuro, debe actualizarse según las tendencias en la epidemiología de la bronquiolitis, y mejorarse mediante su integración con indicadores virológicos. También debe promoverse su inclusión en una estrategia integrada de manejo para la prevención y el control de la bronquiolitis, apoyada por una red de salud pública relacionada con la bronquiolitis.

Palabras clave Bronquiolitis viral; bronquiolitis; Guadalupe; Francia; región del Caribe. 